\title{
A New Model of the Fractional Order Dynamics of the Planetary Gears
}

\author{
Vera Nikolic-Stanojevic, ${ }^{1}$ Ljiljana Veljovic, ${ }^{2}$ and Cemal Dolicanin ${ }^{1}$ \\ ${ }^{1}$ State University of Novi Pazar, Novi Pazar, Serbia \\ ${ }^{2}$ Faculty of Engineering Science, University of Kragujevac, Serbia \\ Correspondence should be addressed to Vera Nikolic-Stanojevic; veranikolic1@gmail.com
}

Received 9 November 2012; Revised 25 March 2013; Accepted 31 March 2013

Academic Editor: Jocelyn Sabatier

Copyright (c) 2013 Vera Nikolic-Stanojevic et al. This is an open access article distributed under the Creative Commons Attribution License, which permits unrestricted use, distribution, and reproduction in any medium, provided the original work is properly cited.

\begin{abstract}
A theoretical model of planetary gears dynamics is presented. Planetary gears are parametrically excited by the time-varying mesh stiffness that fluctuates as the number of gear tooth pairs in contact changes during gear rotation. In the paper, it has been indicated that even the small disturbance in design realizations of this gear cause nonlinear properties of dynamics which are the source of vibrations and noise in the gear transmission. Dynamic model of the planetary gears with four degrees of freedom is used. Applying the basic principles of analytical mechanics and taking the initial and boundary conditions into consideration, it is possible to obtain the system of equations representing physical meshing process between the two or more gears. This investigation was focused to a new model of the fractional order dynamics of the planetary gear. For this model analytical expressions for the corresponding fractional order modes like one frequency eigen vibrational modes are obtained. For one planetary gear, eigen fractional modes are obtained, and a visualization is presented. By using MathCAD the solution is obtained.
\end{abstract}

\section{Introduction}

Planetary gears are a great application in modern engineering systems as a replacement for the conventional manual transmission complex because it has a compact structure and high transmission ratios. Due to the structure of planetary gears and the fact that the so-called planetary gear-satellites simultaneously perform two current trends in the work of planetary gears, there are even extreme vibration, that is, dynamic loads, which cause damage to the gears, bearings, and other elements of the transmission. Precise study of the dynamic behavior of planetary gear is often a difficult mathematical problem, because there are no adequate models. In the idealization of the attached planetary transmission and selection of appropriate dynamic models usually first allocate primary properties, which are maintained in solving the task, and then in future work neglect less important characteristics.

In the first papers on the dynamic behavior of gears in use, one notes a great simplification, for example, that all changes have linear character. However, subsequent experimental studies have shown that this approach is not realistic and that the dynamic behavior of gears in the paper is influenced by many factors that cannot be described by linear relationships [1]. These studies have shown that it is especially important to separate the effects that occur between the gear teeth in mesh, the dynamic effects that result in the load bearing of the engine, dynamic errors in transmission, and so forth. Therefore, a number of important research results of the dynamic behavior of gear transmission will be given, with special reference to the planetary gear.

Although gear dynamics has been studied for decades, few studies present a formulation intended for the dynamic response of full gear systems that contain multiple gear meshes, flexible shafts, bearings, and so forth. There are few reliable computational tools for the dynamic analysis of general gear configurations. Some models exist, but they are limited by simplified modeling of gear tooth mesh interfaces, two-dimensional models that neglect out of plane behavior, and models specific to a single gear configuration.

In a series of papers that follow, the fundamental task of analytical gear research is to build a dynamic model. For different analysis purposes, there are several modelling 
choices such as a simple dynamic factor model, compliance tooth model, torsional model, and geared rotor dynamic model, for example, $[2,3]$.

The simplest models are found in a number of textbooks used in education in this field. So, the teeth in meshing action can be modelled as an oscillatory system [4-6] and so forth. This model consists of concentrated masses (each of which represents one gear) connected with elastic and dump element. Applying the basic principles of analytical mechanics and taking the initial and boundary conditions into consideration, it is possible to obtain the system of equations representing physical meshing process between the two or more gears. In order to obtain better results, it is possible to model the elastic element as a nonlinear spring.

Dynamic transmission error is taken as the parameter for modelling of noise in geared transmission. In the last two decades, there is plenty of work concetrated on modelling of the dynamic transmission error for spur and helical gears and representing the influence of the dynamic transmission errors on the level of noise in the geared transmission. Lately, there has been experiments conducted in order to isolate particular noise effects like noise coming from bearing, housing noise, meshing action noise, and backlash noise simply by measuring the dynamic transmission error. Some of the earliest models are represented in [7-10].

Using the free vibration analysis, one calculates critical parameters such as natural frequencies and vibration modes that are essential for almost all dynamic investigations. The free vibration properties are very useful for further analyses of planetary gear dynamics, including eigensensitivity to design parameters, natural frequency veering, planet mesh phasing, and parametric instabilities from mesh stiffness variations $[11,12]$.

Based on the results of the experiments conducted during the gear vibration research, it is to conclude that the excitation is restored every time when a new pair of teeth enters the mesh. Vibrations with natural frequencies dominate the vibration spectrums. The internal dynamic forces in teeth mesh, vibration, and noise are consequences of the change in teeth deformation, teeth impact, gear inertia due to measure, and teeth shape deviation [13].

Paper $[14,15]$ aims to provide insight into the threedimensional vibration of gears by investigating the mechanisms of excitation and nonlinearity coming from the gear tooth mesh.

For different analysis purposes, there are several modelling choices such as a simple dynamic factor model, compliance tooth model, torsional model, and geared rotor dynamic model [6]. Using the free vibration analysis one calculates critical parameters such as natural frequencies and vibration modes that are essential for almost all dynamic investigations. The free vibration properties are very useful for further analyses of planetary gear dynamics, including eigensensitivity to design parameters, natural frequency veering, planet mesh phasing, and parametric instabilities from mesh stiffness variations [16-22]. It is also necessary to systematically study natural frequency and vibration mode sensitivities and their veering characters to identify the parameters critical to gear vibration. In addition, practical gears may be mistuned by mesh stiffness variation, manufacturing imperfections, and assembling errors. For some symmetric structures, such as turbine blades, space antennae, and multispan beams, small disorders may dramatically change the vibration [18, 19]. The following articles $[10,23]$ are related to the nonlinear analysis of dynamic behavior of gears, using experimental methods and the application of finite element method (FEM).

Paper $[24,25]$ examines the nonlinear dynamics of planetary gears by numerical and analytical methods over the meaningful mesh frequency ranges. Concise, closed-form approximations for the dynamic response are obtained by perturbation analysis.

By using three-dimensional finite element analysis, it is possible to model the whole planetary gear and get adequate solutions. Such a solution to the classic gear transmissions is given in the paper [26]. General three-dimensional finite element models for dynamic response are rare because they require significant computational effort. This is accomplished by many time steps required for the transient response to diminish so that steady-state data can be obtained. This study attempts to fill this gap with a general finite element formulation that can be used for full gearbox dynamic analyses.

A finite element formulation for the dynamic response of gear pairs is proposed in $[24,26,27]$ and so forth. Following an established approach in lumped parameter gear dynamic models, the static solution is used as the excitation in a frequency domain solution of the finite element vibration model. The nonlinear finite element/contact mechanics formulation provides an accurate calculation of the static solution and average mesh stiffness that are used in the dynamic simulation. The frequency domain finite element calculation of dynamic response compares well with numerically integrated (time domain) finite element dynamic results and previously published experimental results. Simulation time with the proposed formulation is two orders of magnitude lower than numerically integrated dynamic results. This formulation admits system level dynamic gearbox response, which may include multiple gear meshes, flexible shafts, rolling element bearings, housing structures, and other deformable components.

In the latest research, light fractional order coupling element is used to describe the dynamic behavior of gears and set of constitutive relationships, so the fractional calculus can be successfully applied to obtain results.

The monograph [28-31] contains a basic mathematical description of fractional calculus and some solutions of the fractional order differential equations necessary for applications of the corresponding mathematical description of a model of gear transmission based on the teeth coupling by standard light fractional order element.

In the series of references [32-40], the mixed discretecontinuum or continuum mechanical systems with fractional order creep properties are mathematically described and analytically solved.

Paper [40] presents two models of the geared transmission with two or more shafts. First approach gives a model based on the rigid rotors coupled with rigid gear teeth, with mass distributions not balanced and in the form of the mass 
particles as the series of the mass disturbance of the gears in multistep gear transmission. Using very simple model it is possible and useful to investigate the nonlinear dynamics of the multistep gear transmission and nonlinear phenomena in free and forced dynamics. This model is suitable to explain source of vibrations and big noise, as well as no stability in gear transmission dynamics. Layering of the homoclinic orbits in phase plane is source of a sensitive dependence nonlinear type of regime of gear transmission system dynamics. Second approach gives a model based on the two-step gear transmission taking into account deformation and creeping and also viscoelastic teeth gears coupling. This investigation was focused to a new model of the fractional order dynamics of the gear transmission. For this model we obtain analytical expressions for the corresponding fractional order modes like one frequency eigen vibrational modes. Generalization of this model to the similar model of the multistep gear transmission is very easy.

The model in this paper represents dynamic model of the planetary gears with four degrees of freedom. Our investigation was focused to a new model of the fractional order dynamics of the planetary gears. For this model we obtain analytical expressions for the corresponding fractional order modes like one frequency eigen vibrational modes.

\section{Mathematical Model of the Planetary Gear}

In the practice, planetary gears are very often exposed to action of forces that change with time (dynamic load). There are also internal dynamic forces present. The internal dynamic forces in gear teeth meshing are the consequence of elastic deformation of the teeth and defects in manufacture such as pitch differences of meshed gears and deviation of shape of tooth profile. Deformation of teeth results in the so-called collision of teeth which is intensified at greater difference in the pitch of meshed gears. Occurrence of internal dynamic forces results in vibration of gears so that the meshed gears behave as an oscillatory system. This model consists of reduced masses of the gear with elastic and damping connections (see $[6,14,15,26,27])$. By applying the basic principles of mechanics and taking into consideration initial and boundary conditions, the system of equation is established which describes physicality of the gear meshing process. On the other hand, extremely cyclic loads (dynamic forces) can result in breakage of teeth, thus causing failure of the mechanism or system.

Primary dependences between geometrical and physical quantities in the mechanics of continuum (and with planetary gear as well) include mainly establishing the constitutive relation between the stress state and deformation state of the tooth's material in the two teeth in contact for each particular case. Thus, solving this task, it is necessary to reduce numerous kinetic parameters to minimal numbers and obtain a simple abstract model describing main properties for investigation of corresponding dynamical influences.

Based on previous, at starting this part, we take into account that contact between two teeth is possible to be constructed by standard light element with constitutive stress-strain state relations which can be expressed by fractional order derivatives.

The papers $[29,39]$ analyzed in details the standard light coupling elements of negligible mass in the form of axially stressed rod without bending, which has the ability to resist deformation under static and dynamic conditions.

Figure 1 shows the model planetary gear when the coupling between the teeth (sun-planet and ring-planet meshes) was obtained from a standard light fractional element. The planetary gear model consists of three members (the sun, 3 planets, and ring).

The motion of the sun gear and the ring gear is given by translations that is expressed as $y_{i}, i=1,2\left(\vec{r}_{i}, i=1,2\right)$, and rotations that is expressed as $\varphi_{i}, i=1,2$. The kinetic energy $E_{K}$ of the planetary stage can be written as

$$
E_{K}=\sum_{i=1}^{2} E_{K i}
$$

The kinetic energy for the each element is represented by

$$
E_{K i}=\frac{1}{2} m_{i} \vec{v}_{i} \cdot \vec{v}_{i}+\frac{1}{2} J_{i} \omega_{i}^{2}, \quad i=1,2,
$$

where $m_{i}$ are masses of the sun gear and ring gear, $J_{i}$ are mass moments of the inertia, $\vec{v}_{i}$ are velocities of mass centers, and $\omega_{i}$ are angular velocities of the sun gear and ring gear.

So, the total kinetic energy of the planetary stage is given by

$$
E_{K}=\frac{1}{2} m_{1} \dot{y}_{1}^{2}+\frac{1}{2} J_{1} \dot{\varphi}_{1}^{2}+\frac{1}{2} m_{2} \dot{y}_{2}^{2}+\frac{1}{2} J_{2} \dot{\varphi}_{2}^{2}
$$

Sun gear is supported with bearing which is modeled as linear spring $c_{10}$, and planet gear is supported with bearing which is modeled as linear spring $c_{20}$, but the meshes of sun gear-planet gear and ring gear-planet gear are described by standard light fractional element with restitution forces $P_{1}(t)$ and $P_{2}(t)$. Thus, the potential energies of the bearings are

$$
E_{P}=\frac{1}{2} c_{10} y_{1}^{2}+\frac{1}{2} c_{20} y_{2}^{2} .
$$

The restitution forces are in the function of element elongation $x_{i}(t)$, and they are in the form

$$
P_{i}(t)=-\left\{c_{i} x_{i}(t)+c_{\alpha} D_{\alpha}^{\prime}\left[x_{i}(t)\right]\right\}, \quad i=1,2 .
$$

The fractional order differential operator $D_{\alpha}^{/}[*]$ of the $\alpha$ th derivative with respect to time $t$ is given in following form: $[32,33,39]$

$$
D_{\alpha}^{\prime}\left[x_{i}(t)\right]=\frac{d^{\alpha} x_{i}(t)}{d t^{\alpha}}=\frac{1}{\Gamma(1-\alpha)} \frac{d}{d t} \int_{0}^{t} \frac{x_{i}(\tau)}{(t-\tau)^{\alpha}} d \tau,
$$

where $c_{i}, c_{\alpha}$ are rigidity momentary and prolonged coefficients and $\alpha$ is rational number $(0<\alpha<1)$.

The equations of motion for the planetary gear are derived from Lagrange's equation given by well-known form

$$
\frac{d}{d t}\left(\frac{\partial E_{K}}{\partial \dot{q}_{j}}\right)-\frac{\partial E_{K}}{\partial q_{j}}+\frac{\partial E_{P}}{\partial q_{j}}=Q_{j}^{*}-\frac{\partial \Phi}{\partial \dot{q}_{j}}, \quad j=1,2, \ldots, 4,
$$




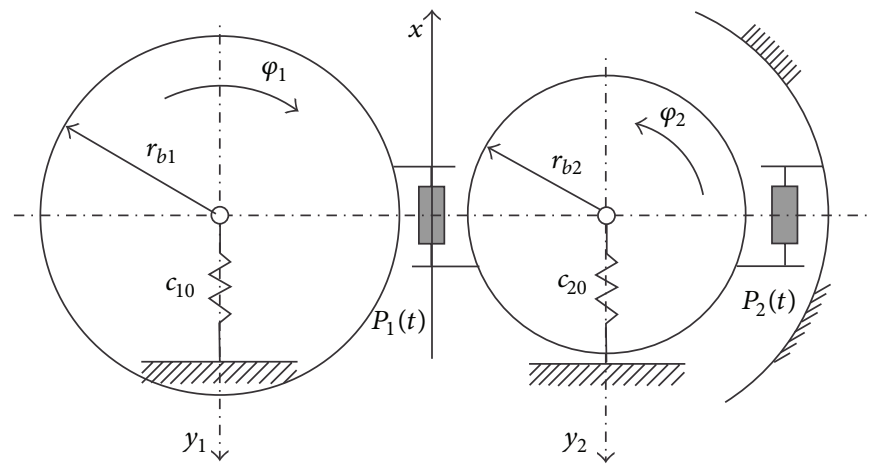

(a)

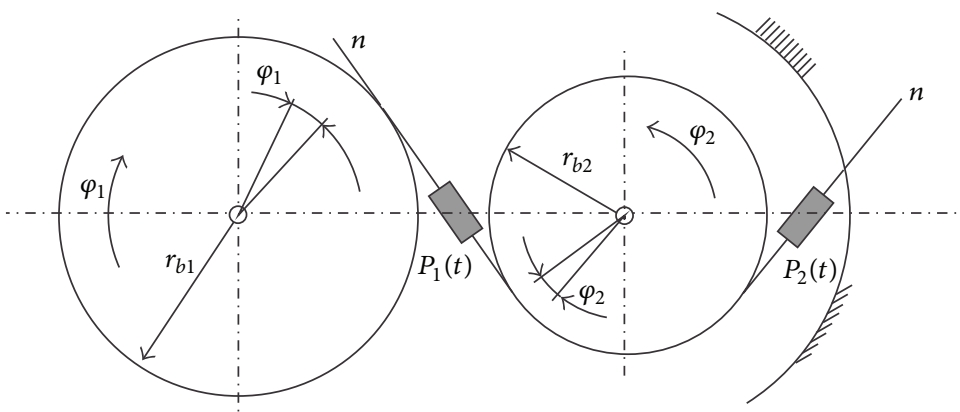

(b)

FIGURE 1: The model of the planetary gear with viscoelastic fractional order tooth coupling: (a) the frontal plane, (b) the direction of contact.

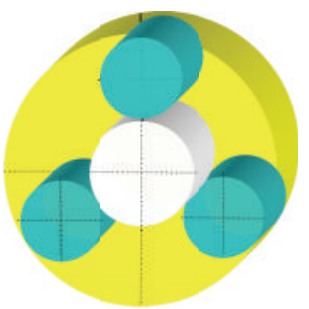

(a) The initial configuration of planetary gear

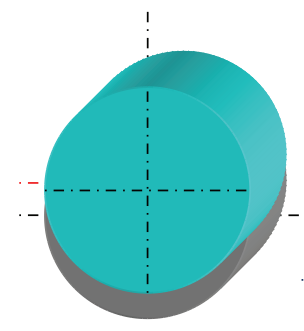

Sun gear
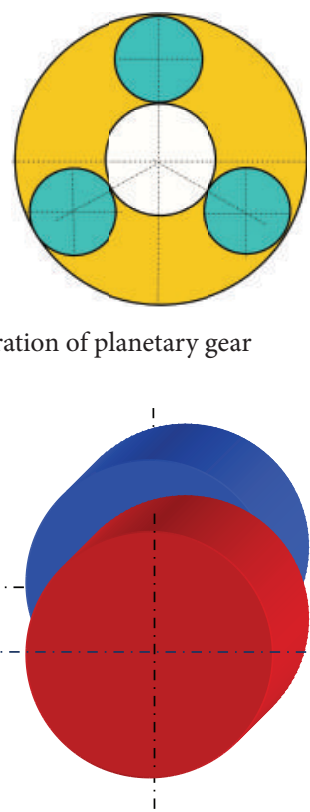

Planet gear

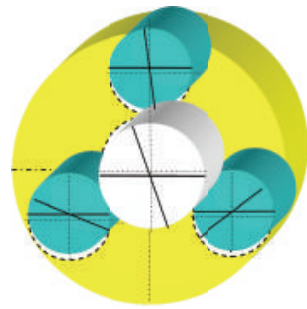

(b) First mode of the planetary gear

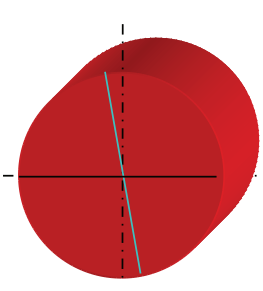

Sun gear

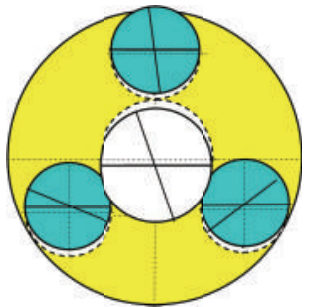

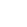




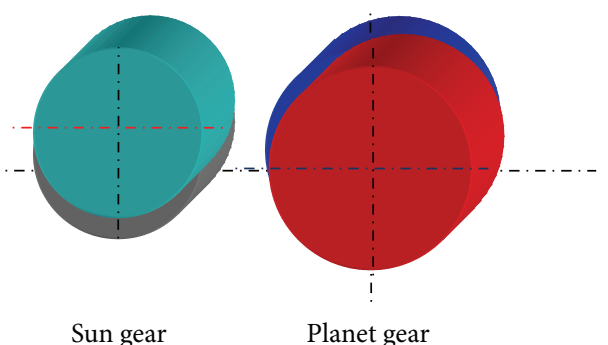

(a)

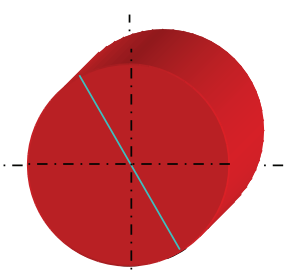

Sun gear

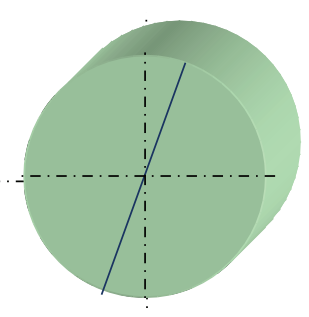

Planet gear

(b)

FIGURE 3: A pair of degenerate translational (a) and angular (b) displacements-eigen amplitudes for second modes of the planetary gear system defined in Table 1. Translational (a) and angular (b) displacements-eigen amplitudes for $\omega_{2}=2901 \mathrm{~Hz}$.

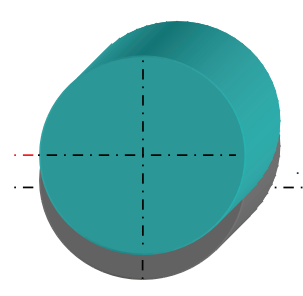

Sun gear

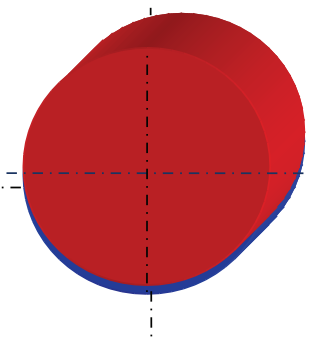

Planet gear

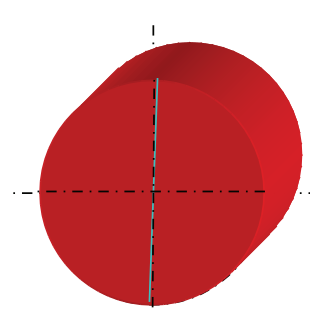

Sun gear

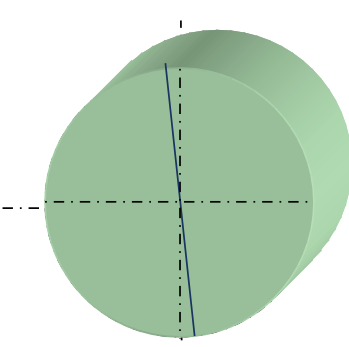

Planet gear

(a)

(b)

Figure 4: A pair of degenerate translational (a) and angular (b) displacements-eigen amplitudes for second modes of the planetary gear system defined in Table 1. Translational (a) and angular (b) displacements-eigen amplitudes for $\omega_{3}=40890 \mathrm{~Hz}$.

where $q_{j}$ are generalized coordinates, $Q_{j}^{*}$ are generalized forces, and $\Phi$ is Rayleigh dissipation function (in our case Rayleigh dissipation function is zero because damping effects are taken into consideration). Generalized coordinates for the given system are $y_{1}, y_{2}, \varphi_{1}$, and $\varphi_{2}$.

Therefore, the dynamic behavior will be governed by four independent equations of motion. In matrix form they are

$$
\mathbf{M}\{\ddot{q}\}+\mathbf{C}\{q\}=Q_{j}^{*}-\frac{\partial \Phi}{\partial \dot{q}_{j}}, \quad j=1,2, \ldots, 4,
$$

where the matrix $\mathbf{M}$ is diagonal inertia matrix and the matrix $\mathrm{C}$ is stiffness matrix.

Light standard creep constraint element between sun gear and planet gear is strained for $x_{1}=y_{2}-y_{1}+r_{b 2} \varphi_{2}-r_{b 1} \varphi_{1}$, and light standard creep constraint element between planet gear and ring gear is strained for $x_{2}=y_{2}-r_{b 2} \varphi_{2}$.

So, due to the constitutive relation of the standard light fractional order coupling elements, the generalized forces as a function of elongation of elements are

$$
\begin{aligned}
Q_{1}^{*}= & -c_{1} x_{1}-c_{\alpha} D_{\alpha}^{\prime}\left[x_{1}\right] \\
= & -c_{1}\left[\left(y_{2}+r_{b 2} \varphi_{2}\right)-\left(y_{1}+r_{b 1} \varphi_{1}\right)\right] \\
& -c_{\alpha} D_{\alpha}^{\prime}\left[\left(y_{2}+r_{b 2} \varphi_{2}\right)-\left(y_{1}+r_{b 1} \varphi_{1}\right)\right], \\
Q_{2}^{*}= & -c_{2} x_{2}-c_{\alpha} D_{\alpha}^{\prime}\left[x_{2}\right] \\
= & -c_{2}\left[y_{2}-r_{b 2} \varphi_{2}\right]-c_{\alpha} D_{\alpha}^{\prime}\left[y_{2}-r_{b 2} \varphi_{2}\right] .
\end{aligned}
$$

Lagrange equations of motion are obtained following substitution (9) into (7), and they can be expressed as

$$
\begin{gathered}
m_{1} \ddot{y}_{1}+c_{01} y_{1}+c_{1}\left[\left(y_{1}+r_{b 1} \varphi_{1}\right)-\left(y_{2}+r_{b 2} \varphi_{2}\right)\right] \\
=c_{\alpha} D_{\alpha}^{\prime}\left[\left(y_{2}+r_{b 2} \varphi_{2}\right)-\left(y_{1}+r_{b 1} \varphi_{1}\right)\right], \\
J_{1} \ddot{\varphi}_{1}+c_{1}\left[\left(y_{1}+r_{b 1} \varphi_{1}\right)-\left(y_{2}+r_{b 2} \varphi_{2}\right)\right] r_{b 1} \\
=c_{\alpha} D_{\alpha}^{\prime} r_{b 1}\left[\left(y_{2}+r_{b 2} \varphi_{2}\right)-\left(y_{1}+r_{b 1} \varphi_{1}\right)\right],
\end{gathered}
$$

$$
\begin{aligned}
m_{2} \ddot{y}_{2} & +c_{02} y_{2} \\
& +c_{1}\left[\left(y_{2}+r_{b 2} \varphi_{2}\right)-\left(y_{1}+r_{b 1} \varphi_{1}\right)\right] \\
& +c_{2}\left[\left(y_{2}-r_{b 2} \varphi_{2}\right)\right] \\
= & c_{\alpha} D_{\alpha}^{/}\left[\left(y_{1}+r_{b 1} \varphi_{1}\right)-\left(y_{2}+r_{b 2} \varphi_{2}\right)\right] \\
& -c_{\alpha} D_{\alpha}^{\prime}\left[\left(y_{2}-r_{b 2} \varphi_{2}\right)\right],
\end{aligned}
$$

$$
\begin{aligned}
J_{2} \ddot{\varphi}_{2} & +c_{1}\left[\left(y_{2}+r_{b 2} \varphi_{2}\right)-\left(y_{1}+r_{b 1} \varphi_{1}\right)\right] r_{b 2} \\
& +c_{2}\left[r_{b 2} \varphi_{2}-y_{2}\right] r_{b 2} \\
= & c_{\alpha} D_{\alpha}^{\prime}\left[\left(y_{1}+r_{b 1} \varphi_{1}\right)-\left(y_{2}+r_{b 2} \varphi_{2}\right)\right] \\
& +c_{\alpha} D_{\alpha}^{\prime}\left[\left(y_{2}-r_{b 2} \varphi_{2}\right)\right] .
\end{aligned}
$$




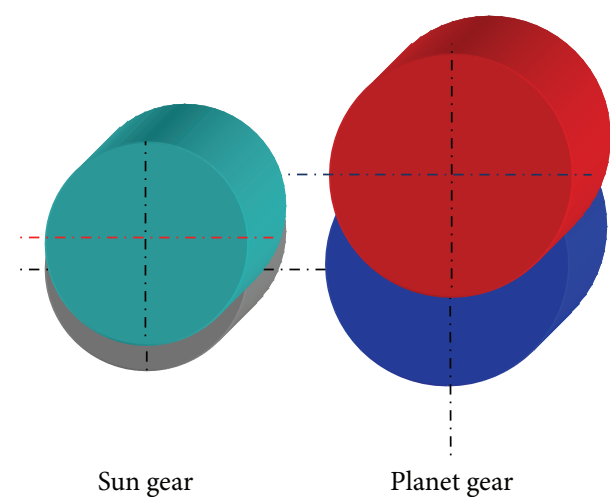

(a)

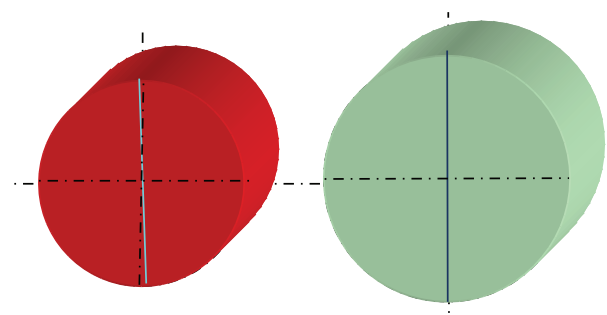

Sun gear
Planet gear

(b)

Figure 5: Fourth rotational-axial modes of the planetary gear system defined in Table 1. Translational (a) and angular (b) displacements-eigen amplitudes for $\omega_{4}=50000 \mathrm{~Hz}$.

The diagonal inertia matrix $\mathbf{M}$ is

$$
\mathbf{M}=\operatorname{diag}\left(m_{1}, J_{1}, m_{2}, J_{2}\right) .
$$

The stiffness matrix $\mathbf{C}$ is

$$
\mathbf{C}=\left[\begin{array}{cccc}
c_{10}+c_{1} & c_{1} r_{b 1} & -c_{1} & -c_{1} r_{b 2} \\
& c_{1} r_{b 1}^{2} & -c_{1} r_{b 1} & -c_{1} r_{b 1} r_{b 2} \\
\text { Symmetric } & & c_{20}+c_{1}+c_{2} & \left(c_{1}-c_{2}\right) r_{b 2} \\
& & & \left(c_{1}+c_{2}\right) r_{b 2}^{2}
\end{array}\right]
$$

\section{Modal Analysis of the Planetary Gear}

The system is tuned, that is, all sun-planet and ring-planet mesh stiffnesses, and their centers of stiffnesses, are identical among all planets; the planet bearing stiffnesses, the axial locations of the planet bearings, and the planet inertias are the same for all planets.
3.1. Eigenvalue Problem. The proposed solutions are in the form of

$$
\{q\}=\{A\} \cos (\omega t+\varepsilon) .
$$

The eigenvalue problem is

$$
(\mathbf{C}-\lambda \mathbf{M})\{q\}=0
$$

with natural frequencies $\sqrt{\lambda}$.

It is known that to have nontrivial solutions the matrix on the left side must be singular. It follows that the determinant of the matrix must be equal to 0 , so

$$
\operatorname{det}(\mathbf{C}-\lambda \mathbf{M})=0
$$

or, in the developed form,

$$
\left[\begin{array}{cccc}
\left(c_{10}+c_{1}\right)-\lambda m_{1} & c_{1} r_{b 1} & -c_{1} & -c_{1} r_{b 2} \\
& \left(c_{1} r_{b 1}^{2}\right)-\lambda J_{1} & -c_{1} r_{b 1} & -c_{1} r_{b 1} r_{b 2} \\
\text { Symmetric } & & \left(c_{20}+c_{1}+c_{2}\right)-\lambda m_{2} & \left(c_{1}-c_{2}\right) r_{b 2} \\
& & & \left(\left(c_{1}+c_{2}\right) r_{b 2}^{2}\right)-\lambda J_{2}
\end{array}\right]=0 .
$$

Corresponding frequency equation in the polynomial form is

$$
a_{4} \lambda^{4}+a_{3} \lambda^{3}+a_{2} \lambda^{2}+a_{1} \lambda+a_{0}=0
$$

where, for instance, $a_{4}=\operatorname{trace} \mathbf{M}, a_{0}=\operatorname{det} \mathbf{C}$, and so forth.

Solving this polynomial four roots $\lambda_{j}, j=1,2,3,4$ and corresponding eigen circular frequencies $\omega_{j}=\sqrt{\lambda_{j}}, j=$ $1,2,3,4$, can be obtained.

The solution of basic linear differential equation is

$$
q_{j}(t)=\sum_{s=1}^{4} q_{j}^{(s)}(t)=\sum_{s=1}^{4} A_{j}^{(s)} \cos \left(\omega_{s} t+\varepsilon_{s}\right),
$$



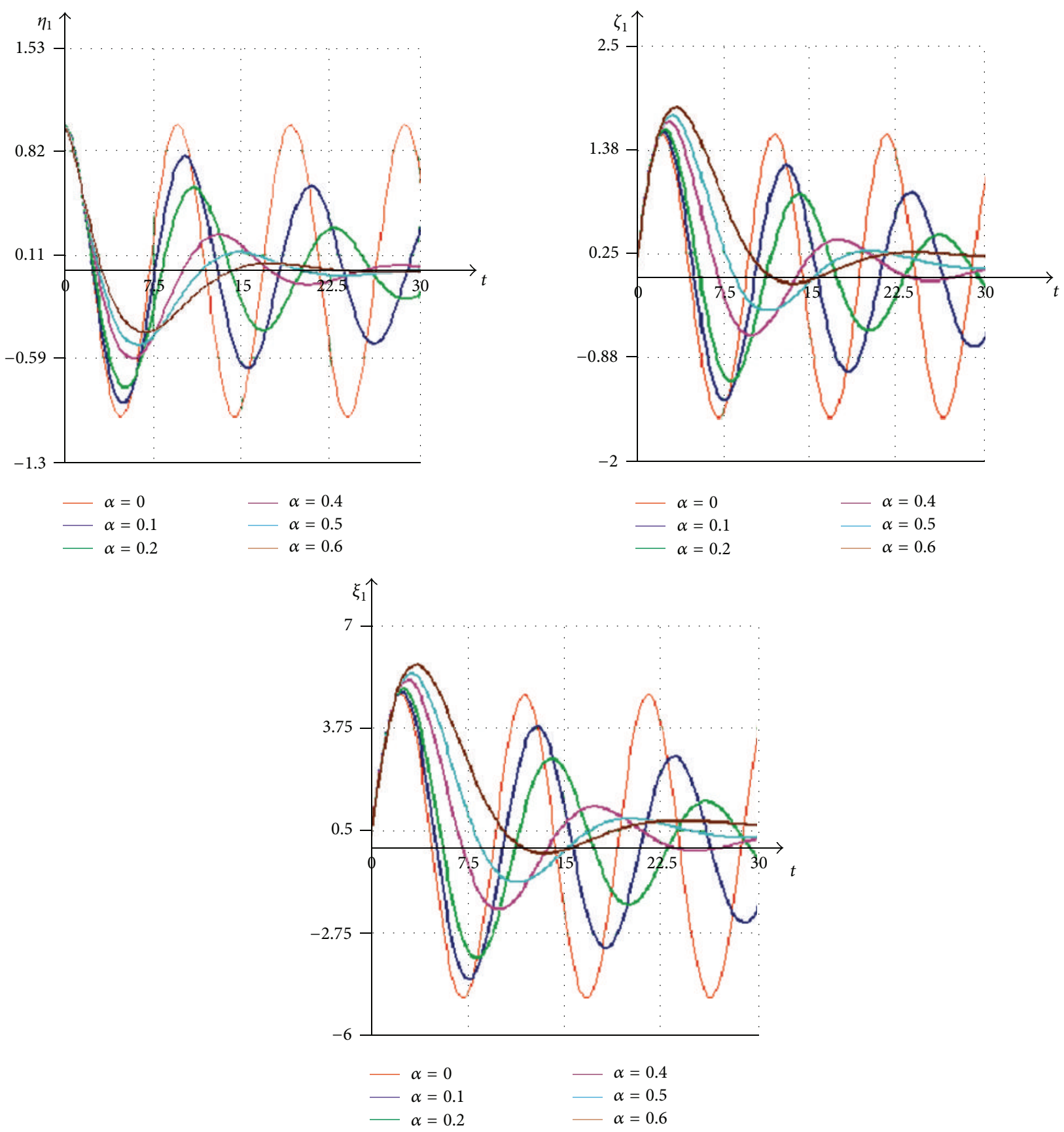

FiguRE 6: First eigen fractional mode $\xi_{1}(t)$ with corresponding first fractional order time components $\eta_{1}(t)$ and $\zeta_{1}(t)$ for different system kinetic and geometric parameter values.

and in matrix presentation

$$
\{q(t)\}=\mathbf{R}\left\{C_{s} \cos \left(\omega_{s} t+\varepsilon_{s}\right)\right\}
$$

where $\mathbf{R}$ is modal matrix defined by the corresponding cofactors, $\xi_{s}=C_{s} \cos \left(\omega_{s} t+\varepsilon_{s}\right)$, and $s=1,2,3,4$ are main coordinates of the linear system.
With this expression, the system of the fractional differential equation (10) can be transformed in the form of [39]

$$
\ddot{\xi}_{s}+\omega_{s}^{2} \xi_{s}=-\omega_{\alpha s}^{2} D_{\alpha}^{\prime}\left[\xi_{s}\right], \quad s=1,2,3,4
$$

This resulted the system of the fractional differential equation. Analytical solution of these fractional order differential equations is obtained using the approach presented in 

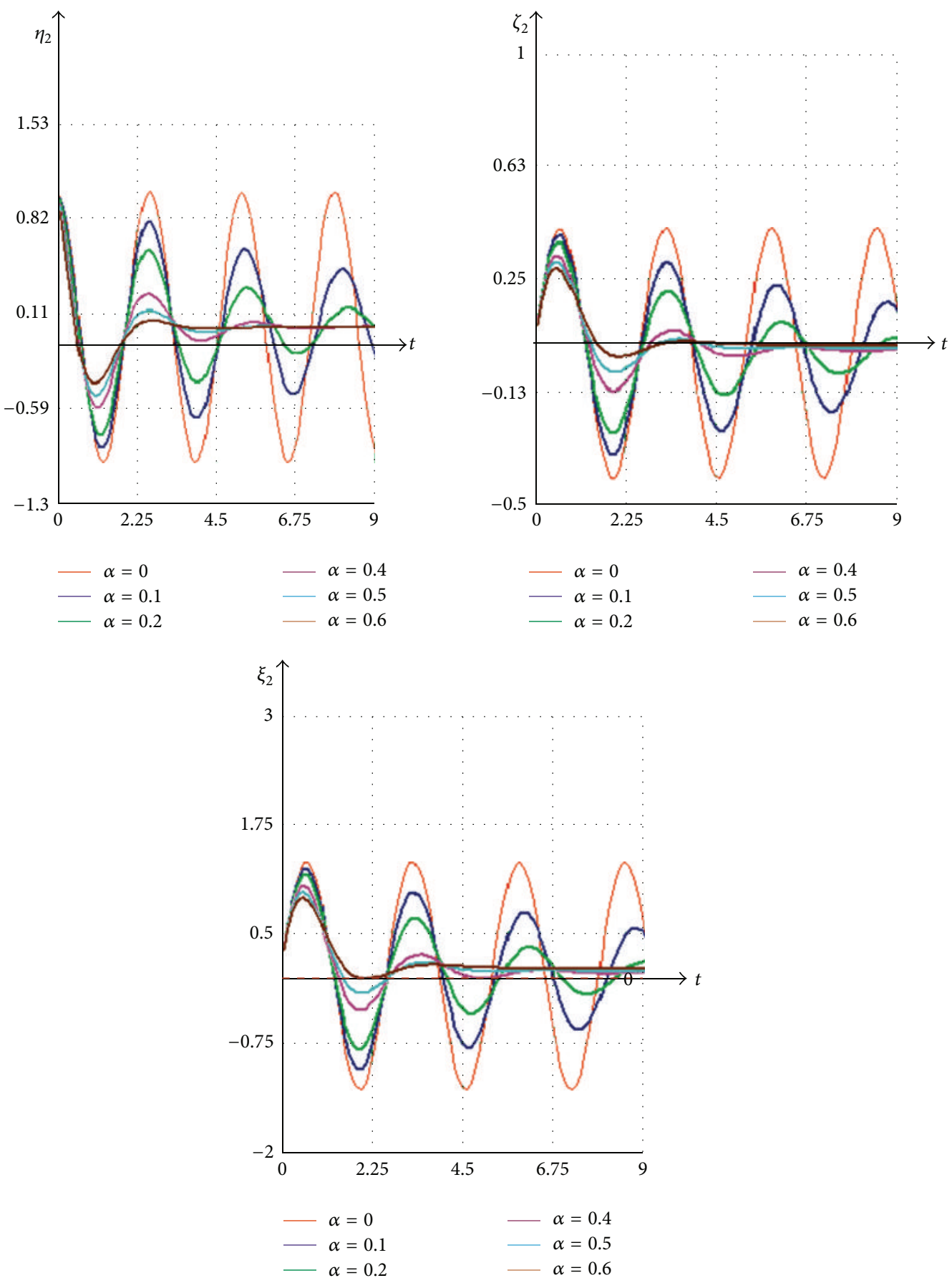

FIGURE 7: Second eigen fractional mode $\xi_{2}(t)$ with corresponding second fractional order time components $\eta_{2}(t)$ and $\zeta_{2}(t)$ for different system kinetic and geometric parameter values.

$[37,39]$. Therefore, each fractional differential equation can be written in the form of

$$
\xi_{s}(t)=\xi_{0 s} \sum_{k=0}^{\infty}(-1)^{k} \omega_{\alpha s}^{2 k} t^{2 k}
$$

$$
\begin{aligned}
& \times \sum_{j=0}^{k}\left(\begin{array}{c}
k \\
j
\end{array}\right) \frac{(\mp 1)^{j} \omega_{\alpha s}^{2 j} t^{-\alpha j}}{\omega_{s}^{2 j} \Gamma(2 k+1-\alpha j)} \\
& +\dot{\xi}_{0 s} \sum_{k=0}^{\infty}(-1)^{k} \omega_{\alpha s}^{2 k} t^{2 k+1} \\
& \times \sum_{j=0}^{k}\left(\begin{array}{c}
k \\
j
\end{array}\right) \frac{(\mp 1)^{j} \omega_{\alpha s}^{-2 j} t^{-\alpha j}}{\omega_{s}^{2 j} \Gamma(2 k+2-\alpha j)}, \quad s=1,2,3,4,
\end{aligned}
$$



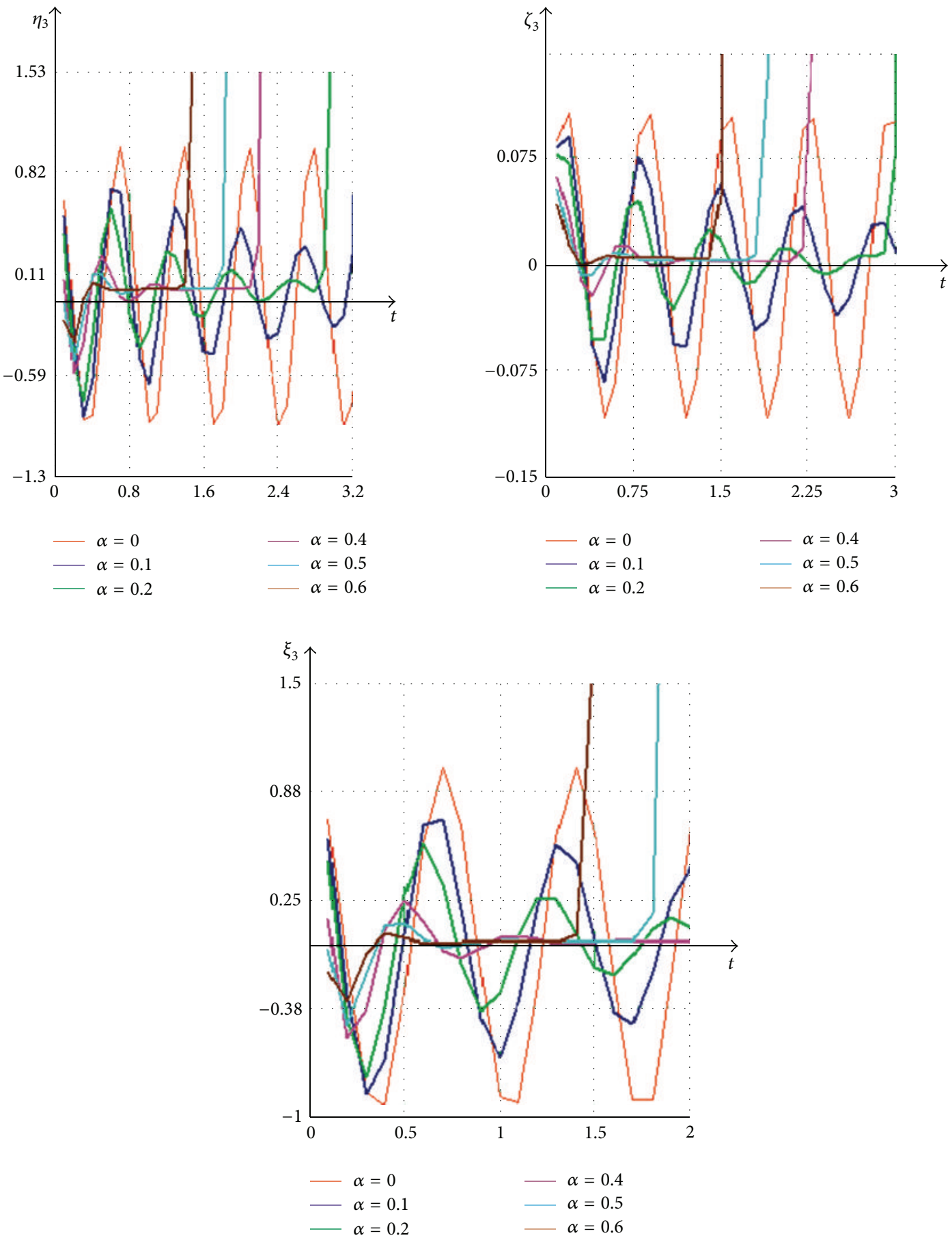

FIGURE 8: Third eigen fractional mode $\xi_{3}(t)$ with corresponding third fractional order time components $\eta_{3}(t)$ and $\zeta_{3}(t)$ for different system kinetic and geometric parameter values.

where $\xi_{s}(0)=\xi_{0 s}$ and $\dot{\xi}_{s}(0)=\dot{\xi}_{0 s}$ are initial values of main coordinates defined by initial conditions and $\alpha$ is rational number $(0<\alpha<1)$.

The solution of the basis system [39] can be expressed in the following form:

$$
\begin{aligned}
q_{j}(t) & =\sum_{s=1}^{4} K_{p k}^{(s)} \xi_{s}(t) \\
& =\sum_{s=1}^{4} K_{p k}^{(s)} \xi_{0 s} \sum_{k=0}^{\infty}(-1)^{k} \omega_{\alpha s}^{2 k} t^{2 k}
\end{aligned}
$$

$$
\begin{aligned}
& \times \sum_{j=0}^{k}\left(\begin{array}{c}
k \\
j
\end{array}\right) \frac{(\mp 1)^{j} \omega_{\alpha s}^{2 j} t^{-\alpha j}}{\omega_{s}^{2 j} \Gamma(2 k+1-\alpha j)} \\
& +\sum_{s=1}^{4} K_{p k}^{(s)} \dot{\xi}_{0 s} \sum_{k=0}^{\infty}(-1)^{k} \omega_{\alpha s}^{2 k} t^{2 k+1} \\
& \times \sum_{j=0}^{k}\left(\begin{array}{c}
k \\
j
\end{array}\right) \frac{(\mp 1)^{j} \omega_{\alpha s}^{-2 j} t^{-\alpha j}}{\omega_{s}^{2 j} \Gamma(2 k+2-\alpha j)}, \quad s=1,2,3,4 .
\end{aligned}
$$



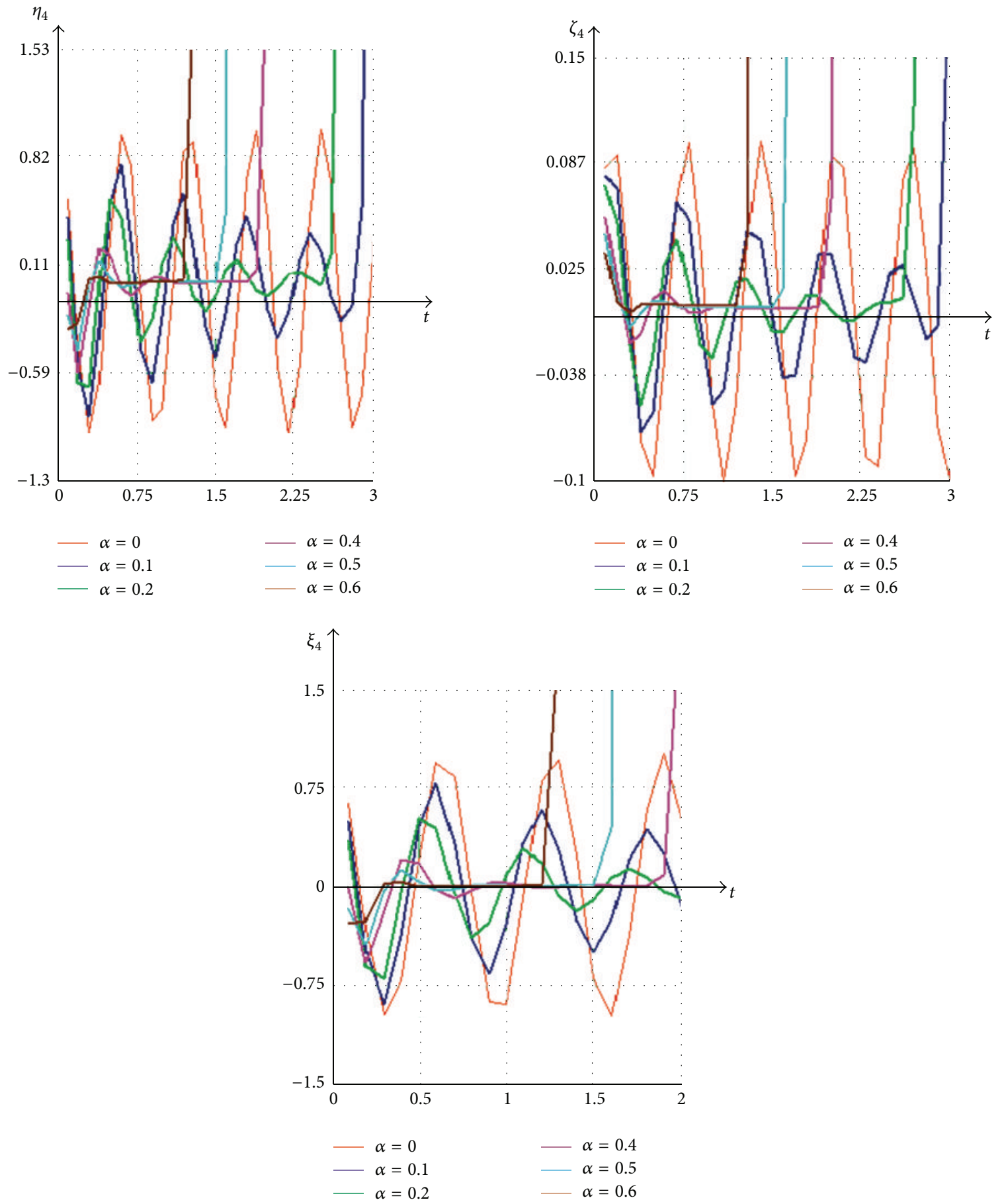

FIGURE 9: Fourth eigen fractional mode $\xi_{4}(t)$ with corresponding third fractional order time components $\eta_{4}(t)$ and $\zeta_{4}(t)$ for different system kinetic and geometric parameter values.

3.2. Numerical Visualisation. Eigensolutions of a sample system [20, Table 1], with four degrees of freedom are evaluated numerically to expose the modal properties.

Eigensolutions of a sample system (Table 1) with three equally spaced planets are evaluated numerically to expose the modal properties. Four natural frequencies and their corresponding mode types are given in Figures 2, 3, 4, and 5. In Figure 2(a), the initial configuration of planetary gear is shown, and Figure 2(b) shows the planetary gear first mode. In order to better consideration of modes of individual elements of the gear in the following Figures 2(c), 2(d), 3, 4 and 5 , separate elements of planetary gear are shown.

The vibration modes exhibit distinctive characteristics. The central member rotates and translates axially and planets do same. Regardless of the system parameters the modal deflection of planet gears are zero for $\omega_{4}=50000 \mathrm{~Hz}$. 

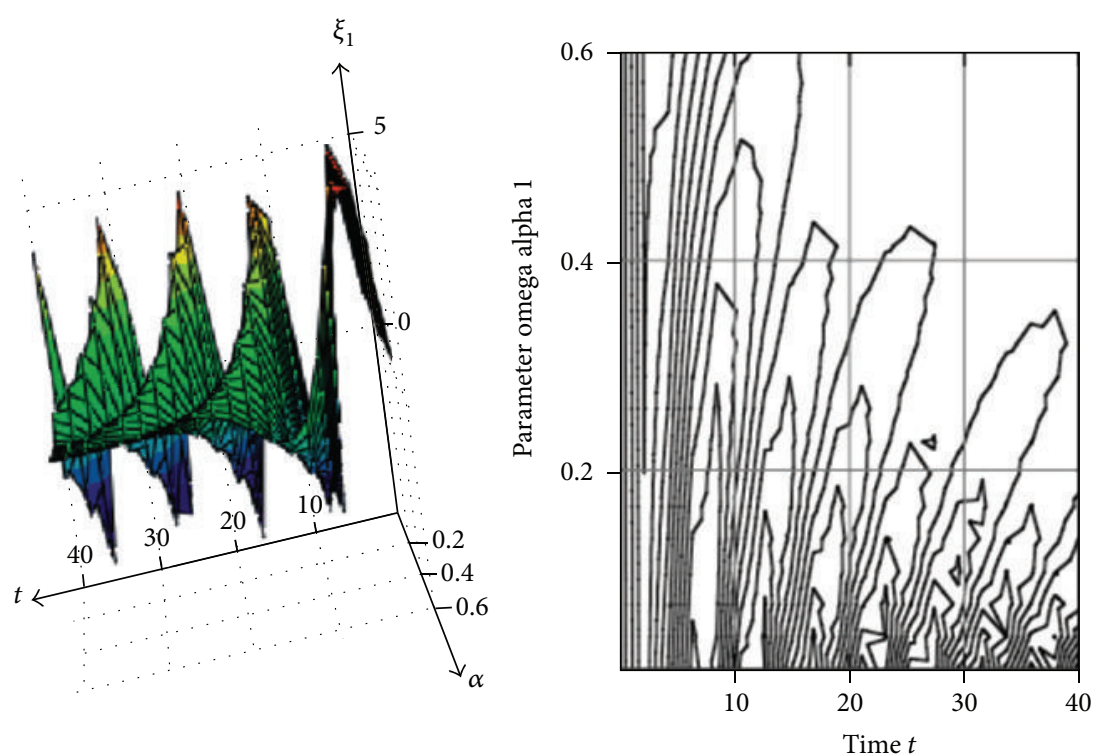

(a) First mode of the planetary gear system $\xi_{1}(\alpha, t)$
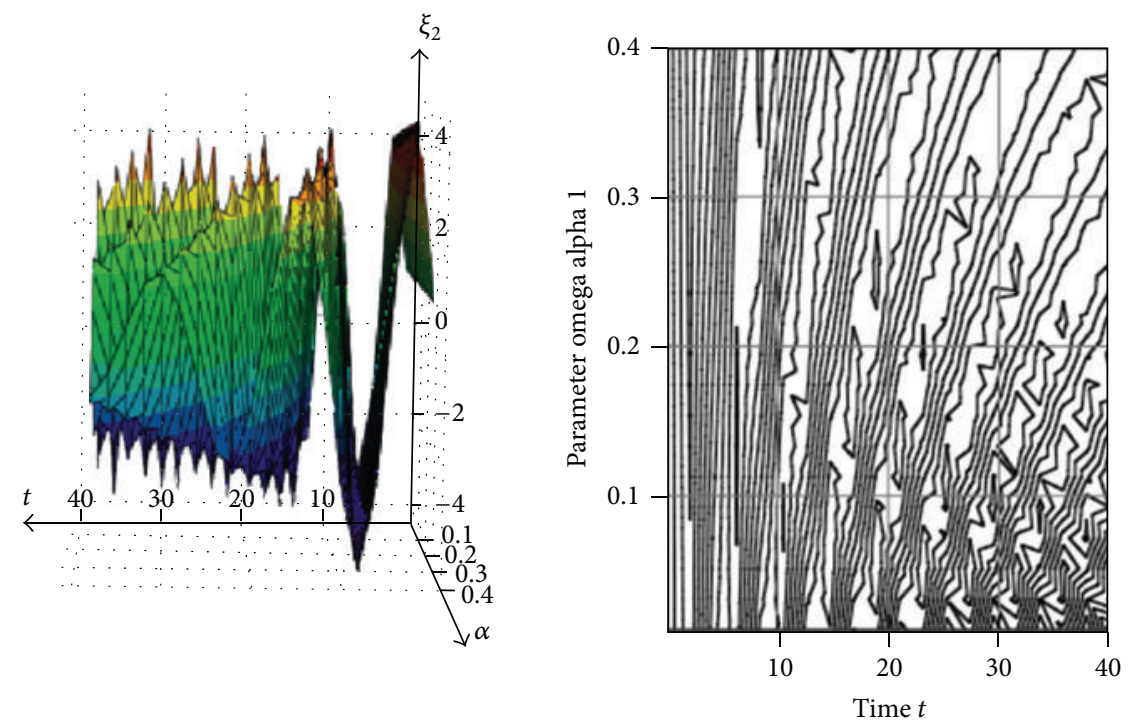

(b) Second mode of the planetary gear system $\xi_{2}(\alpha, t)$
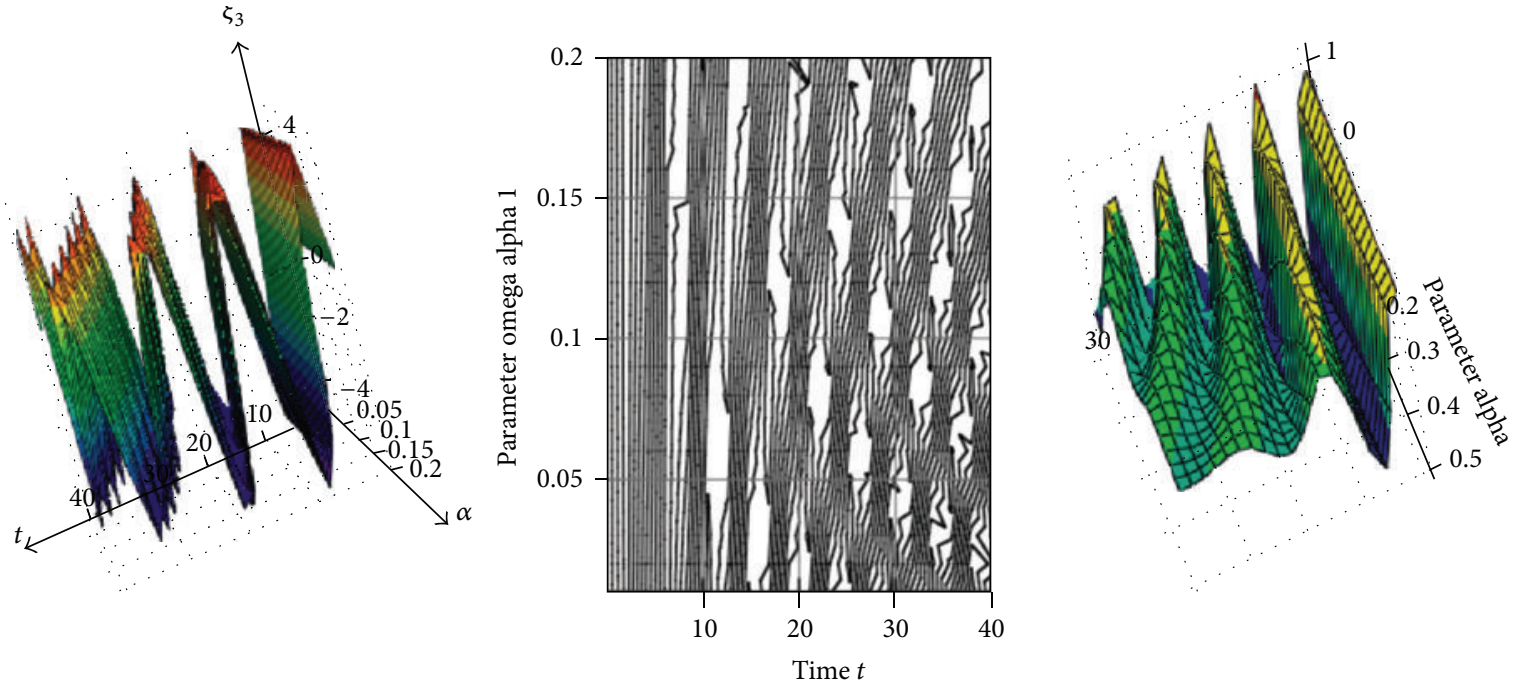

(c) Third mode of the planetary gear system $\xi_{3}(\alpha, t)$ Figure 10: Continued.
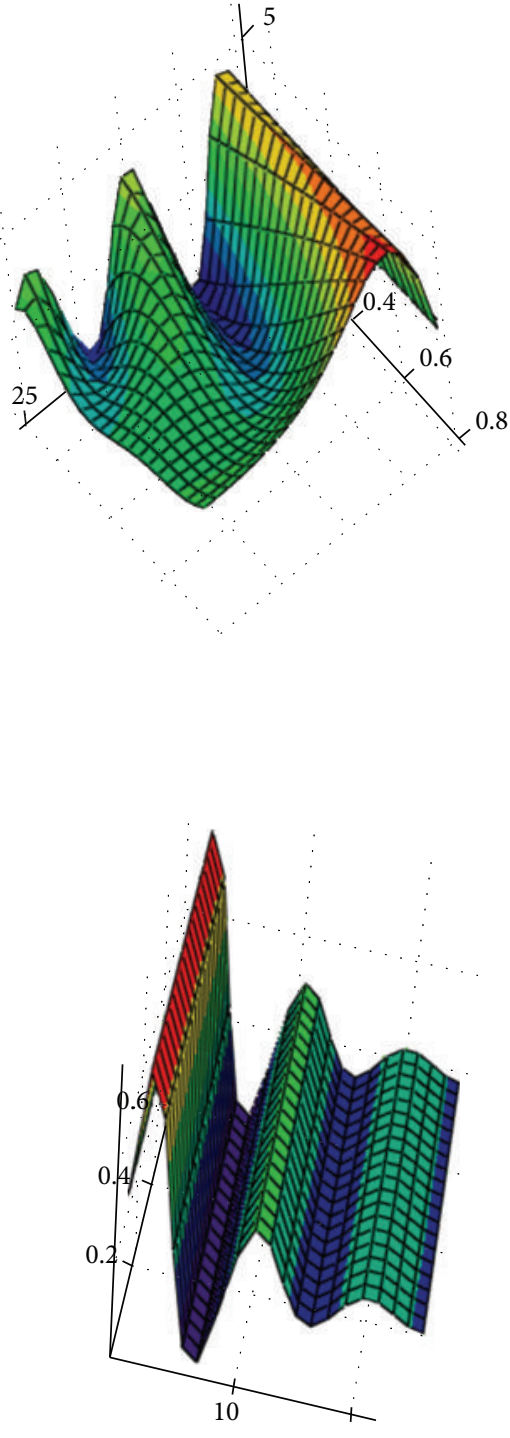

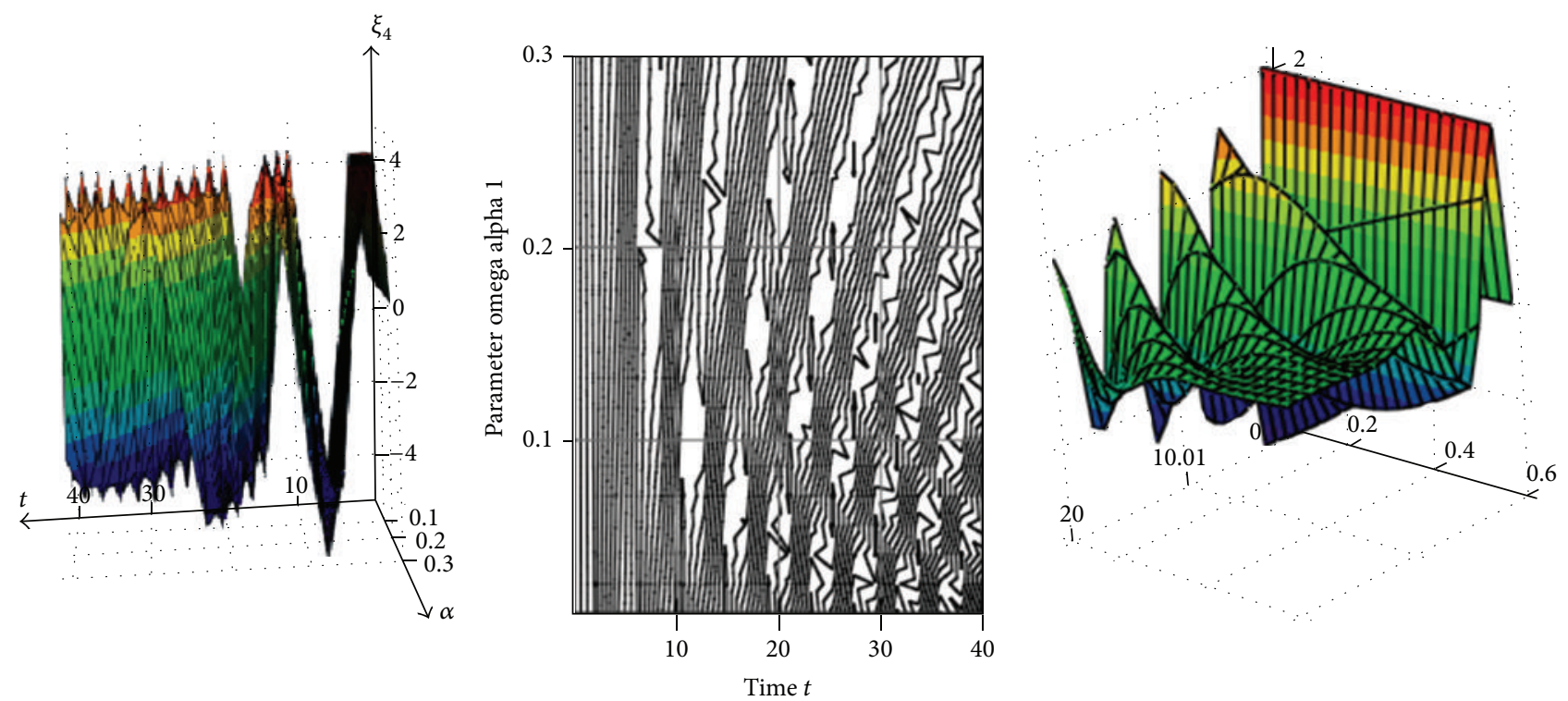

(d) Fourth mode of the planetary gear system $\xi_{4}(\alpha, t)$

FIGURE 10: Four eigen fractional modes, $\xi_{1}(\alpha, t), \xi_{2}(\alpha, t), \xi_{3}(\alpha, t)$, and $\xi_{4}(\alpha, t)$ presented by surfaces.

TABLE 1: Parameters of the planetary gear.

\begin{tabular}{lcc}
\hline Parameter & Sun & Planet \\
\hline Base radius $r_{b}, \mathrm{~mm}$ & 24 & 16 \\
Radial bearing stiffnesses $c_{10}$ and $c_{20}$, & $0.5 \times 10^{9}$ & $0.5 \times 10^{9}$ \\
$\mathrm{~N} / \mathrm{m}$ & $2.91 \times 10^{8}$ & $1.81 \times 10^{8}$ \\
Stiffness of teeth $c_{1}$ and $c_{2}, \mathrm{~N} / \mathrm{m}$ & 0.3 & 0.20 \\
Mass $m, \mathrm{~kg}$ & $10 \times 10^{-3}$ & $100 \times 10^{-6}$ \\
Rotational inertia, $J_{1}, \mathrm{~kg} \mathrm{~m}^{2}$ & & \\
\hline
\end{tabular}

Based on (18), the first normal mode corresponds to both masses moving in the opposite direction while angular displacements are in the same direction. The second normal mode corresponds to the masses moving in the opposite directions and angular displacements are in the opposite directions also. The masses, for $\omega_{3}$ and $\omega_{4}$, move in the same direction, but angular displacements are in the opposite directions or equal zero (fourth mode). The general solution is a superposition of the normal modes where the initial conditions of the problem must be used.

By using different numerical values of the kinetic and geometrical parameters of the planetary gear model, the series of the graphical presentation of the four sets of the two time components $\eta_{s}(t)$ and $\zeta_{s}(t), s=1,2,3,4$ of the solutions, by using expressions (21) are obtained. In the series Figures 6-10 are presented characteristic modes for different values of the $\alpha$ coefficient of the fractional order of the used standard light fractional order element for describing teeth coupling between sun-planet and planet-ring. Time $t$ is in sec, and all values on the vertical axis are in $\mu \mathrm{m}$.

First eigen fractional order mode $\xi_{1}(t)$ with corresponding first eigen fractional order time components $\eta_{1}(t)$ and $\zeta_{1}(t)$ for different system kinetic and geometric parameter values is presented in Figure 6.

In Figure 7, we can see second eigen fractional mode $\xi_{2}(t)$ with corresponding second fractional order time components $\eta_{2}(t)$ and $\zeta_{2}(t)$ for different system kinetic and geometric parameter values.

In Figure 8, third eigen fractional mode $\xi_{3}(t)$ with corresponding third fractional order time components $\eta_{3}(t)$ and $\zeta_{3}(t)$ for different system kinetic and geometric parameter values is presented.

Fourth eigen fractional mode $\xi_{4}(t)$ with corresponding third fractional order time components $\eta_{4}(t)$ and $\zeta_{4}(t)$ for different system kinetic and geometric parameter values, in Figure 9, is presented.

In Figure 10, first, second, third, and fourth eigen fractional modes $\xi_{1}(\alpha, t), \xi_{2}(\alpha, t), \xi_{3}(\alpha, t)$, and $\xi_{4}(\alpha, t)$ are presented by surfaces. Also, the family trajectory in the plane $(\alpha, t)$ is shown.

Based on the obtained results in this paper, we can conclude that eigen fractional order modes are like one frequency vibration modes similar to single frequency eigen mode of the corresponding linear system [29, 38, 39, 41].

The fractional order dynamic system is like dumping system. With the increase of the parameter $\alpha$, the period of oscillation increases but the amplitude becomes smaller. So we can say that parameter $\alpha$ has the same influence as dumping coefficient in the corresponding system.

\section{Conclusions}

This paper presents a new dynamic model of a planetary gear. The planetary gear system is represented by a model that allows for four degrees of freedom per gear-shaft body supported by bearings at arbitrary axial positions and with 
standard creep constraint element. The standard light fractional order coupling element is between sun-planet and planet-ring. A novel approach for the planetary gear dynamic analysis is developed. So, in this paper it is shown how the new model of the fractional order dynamic planetary gear can be applied to study dynamic behavior. This model simulates the real behavior of the planetary gear.

With this simple model, it is possible to research the nonlinear dynamics of the planetary gear and nonlinear phenomena in free and forced dynamics. The model is suitable to explain source of vibrations and big noise, as well as no stability in planetary gear.

A new method, using MATCAD software, is used in this paper for the obtaining of the eigen values and for analysis results.

In the literature, similar procedures are presented in introduction, and they were used as reference material for the composition and verification of models and results.

On the basis of the numerical results, shown in this paper, it has been concluded that the methodology developed to study the dynamic behaviour of planetary gear is very efficient. It gives a lot of possibilities and can be easily upgraded for analysis of other effects.

The dynamic behavior and analysis of results suggest that the gear transmission is very complex and that it is almost impossible to include all the effects by such and similar research. This paper considers planetary gear with 3 planet gears, which makes the problem more complex.

Further research should be directed at studying the effects of mutual dynamic impact of teeth in mesh, as well as at including more effects [42]. So, it is possible to study eigen frequency of planetary gear with moving excentric masses on the body of one of the gears or with holes on the body, by using finite element method.

In accordance with the present trend of application of new materials, authors will, in future studies, simulate the dynamic behavior of a gear made of composite materials and study the life of the gears at the load. Also, future research should focus on the study of planetary gears life using low cycle fatigue properties and so forth.

Results in this paper can be taken as relevant for further research, because this model simulates the real behavior of the planetary gear, more than earlier models.

\section{Acknowledgments}

Parts of this research were supported by the Ministry of Sciences of Republic Serbia through Mathematical Institute SANU Belgrade Grant no. ON 174001 "Dynamics of hybrid systems with complex structures. Mechanics of materials" and also through the Faculty of Mechanical Engineering University of Niš and the State University of Novi Pazar.

\section{References}

[1] F. Cunliffe, D. J. Smith, and D. B. Welbourn, "Dynamic tooth loads in epicyclic gears," Journal of Engineering For Industry, vol. 95, no. 2, pp. 578-584, 1974.
[2] G. W. Blankenship and R. Singh, "Dynamic force transmissibility in helical gear pairs," Mechanism and Machine Theory, vol. 30, no. 3, pp. 323-339, 1995.

[3] G. W. Blankenship and R. Singh, "A new gear mesh interface dynamic model to predict multi-dimensional force coupling and excitation," Mechanism and Machine Theory, vol. 30, no. 1, pp. 43-57, 1995.

[4] G. Liu and R. G. Parker, "Impact of tooth friction and its bending effect on gear dynamics," Journal of Sound and Vibration, vol. 320, no. 4-5, pp. 1039-1063, 2009.

[5] G. Niemann and H. Winter, Maschinen-Elemente II and III, Springer, Berlin, Germany, 1989.

[6] V. Nikolic, Machine Elements, Theory, Calculation, Examples, Faculty of Mechanical Engineering, Prizma, Kragujevac, Serbia, 2004.

[7] V. Nikolic, Mechanical Analysis of Gears, Faculty of Mechanical Engineering, Cimpes, Kragujevac, Serbia, 1999.

[8] G. Liu and R. G. Parker, "Nonlinear dynamics of idler gear systems," Nonlinear Dynamics, vol. 53, no. 4, pp. 345-367, 2008.

[9] A. Kahraman and G. W. Blankenship, "Experiments on nonlinear dynamic behavior of an oscillator with clearance and periodically time-varying parameters," Journal of Applied Mechanics, vol. 64, no. 1, pp. 217-226, 1997.

[10] A. Kahraman and R. Singh, "Non-linear dynamics of a spur gear pair," Journal of Sound and Vibration, vol. 142, no. 1, pp. 49-75, 1990.

[11] R. G. Parker, S. M. Vijayakar, and T. Imajo, "Non-linear dynamic response of a spur gear pair: modelling and experimental comparisons," Journal of Sound and Vibration, vol. 237, no. 3, pp. 435-455, 2000.

[12] J. Lin and R. G. Parker, "Analytical characterization of the unique properties of planetary gear free vibration," Journal of Vibration and Acoustics, vol. 121, no. 3, pp. 316-321, 1999.

[13] L. Vedmar and A. Andersson, "A method to determine dynamic loads on spur gear teeth and on bearings," Journal of Sound and Vibration, vol. 267, no. 5, pp. 1065-1084, 2003.

[14] M. F. Agemi and M. Ognjanović, "Gear vibration in supercritical mesh-frequency range," FME Transactions, vol. 32, no. 2, pp. 8794, 2004.

[15] D. Dimitrijević and V. Nikolić, "Eigenfrequencies analysis for the deep drilling machine gear set," The Scientific Journal FACTA UNIVERSATES, vol. 1, no. 5, pp. 629-636, 1998.

[16] D. Dimitrijevic and V. Nikolic, "Eigenfrequence analysis of the spur gear pair with moving excentric masses on the body of one of the gears," FME Transactions, vol. 35, no. 3, pp. 157-163, 2007.

[17] H. Vinayak and R. Singh, "Multi-body dynamics and modal analysis of compliant gear bodies," Journal of Sound and Vibration, vol. 210, no. 2, pp. 171-212, 1998.

[18] J. Lin and R. G. Parker, "Analytical characterization of the unique properties of planetary gear free vibration," Journal of Vibration and Acoustics, vol. 121, no. 3, pp. 316-321, 1999.

[19] J. Lin and R. G. Parker, "Natural frequency veering in planetary gears," Mechanics of Structures and Machines, vol. 29, no. 4, pp. 411-429, 2001.

[20] J. Lin and R. G. Parker, "Planetary gear parametric instability caused by mesh stiffness variation," Journal of Sound and Vibration, vol. 249, no. 1, pp. 129-145, 2002.

[21] T. Eritenel and R. G. Parker, "Modal properties of threedimensional helical planetary gears," Journal of Sound and Vibration, vol. 325, no. 1-2, pp. 397-420, 2009. 
[22] Y. Guo and R. G. Parker, "Sensitivity of general compound planetary gear natural frequencies and vibration modes to model parameters," Journal of Vibration and Acoustics, vol. 132, no. 1, 13 pages, 2010.

[23] T. Hidaka, Y. Terauchi, and K. Nagamura, "Dynamic behavior of planetary gear," Bulletin of the JSME, vol. 22, no. 169, pp. 10171025, 1979.

[24] R. G. Parker, V. Agashe, and S. M. Vijayakar, "Dynamic response of a planetary gear system using a finite element/contact mechanics model," Journal of Mechanical Design, vol. 122, no. 3, pp. 304-310, 2000.

[25] C. J. Bahk and R. G. Parker, "Analytical solution for the nonlinear dynamics of planetary gears," Journal of Computational and Nonlinear Dynamics, vol. 6, no. 2, Article ID 021007, 15 pages, 2011.

[26] T. Sun and H. Hu, "Nonlinear dynamics of a planetary gear system with multiple clearances," Mechanism and Machine Theory, vol. 38, no. 12, pp. 1371-1390, 2003.

[27] V. Nikolić, C. Dolićanin, and D. Dimitrijević, "Numerical modelling of gear set dynamic behaviour," Scientific Technical Review, no. 3-4, pp. 48-54, 2010.

[28] V. Nikolić, Ć. Dolićanin, and D. Dimitrijević, “Dynamic Model for the Stress and Strain State Analysis of a Spur Gear Transmission, StrojniŔki vestnik," Journal of Mechanical Engineering, vol. 58, no. 1, pp. 56-67, 2012.

[29] O. A. I. Goroško and K. Hedrih, Analitička Dinamika (Mehanika) Diskretnih Naslednih Sistema, (Analytical Dynamics (Mechanics) of Discrete Hereditary Systems), Monograph, University of Niš, 2001.

[30] O. A. Goroško and K. Hedrih, "Advances in development of the analytical dynamics of the hereditary discrete systems," Journal of Physics, vol. 96, Article ID 012143, 2008.

[31] B. S. Bačlić and T. M. Atanacković, "Stability and creep of a fractional derivative order viscoelastic rod," Bulletin, no. 25, pp. 115-131, 2000.

[32] M. T. Atanacković, C. D. Dolićanin, and S. Pilipović, "Forced oscillations of a single degree of freedom system with fractional dissipation," Scientific Publications of the State University of Novi Pazar, vol. 3, no. 1, pp. 1-11, 2011.

[33] K. Hedrih and R. Knežević, "Structural stability of the planetary reductor nonlinear dynamics phase portrait," Facta Universitatis, vol. 1, no. 7, pp. 911-923, 2000.

[34] K. Hedrih, K. Knežević, and R. Cvetković, "Dynamics of planetary reductoe with turbulent damping," International Journal of Nonlinear Sciences and Numerical Simulations, vol. 2, no. 3, pp. 265-262, 2001.

[35] R. G. Parker, "On the eigenvalues and critical speed stability of gyroscopic continua," Journal of Applied Mechanics, vol. 65, no. 1, pp. 134-140, 1998.

[36] K. Hedrih and L. J. Veljović, "Nonlinear dynamic of heavy gyrorotor with two skew rotating axes," Journal of Physics, vol. 96, Article ID 012221, 2008.

[37] K. Hedrih and L. J. Veljović, "Nonlinear dynamic of heavy gyro-rotor with two rotating axes, facta universitates series mechanics," Automatic Control and Robotics, vol. 14, no. 16, pp. 55-68, 2004.

[38] K. R. Hedrih and L. Veljović, "Vector rotators of rigid body dynamics with coupled rotations around axes without intersection," Mathematical Problems in Engineering, vol. 2011, Article ID 351269, 26 pages, 2011.
[39] K. R. Hedrih, "Dynamics of multi-pendulum systems with fractional order creep elements," Journal of Theoretical and Applied Mechanics, vol. 46, no. 3, pp. 483-509, 2008.

[40] K. S. Hedrih and V. Nikolić-Stanojević, "A model of gear transmission fractional order system dynamics," Mathematical Problems in Engineering, vol. 2010, Article ID 972873, 23 pages, 2010.

[41] S. Vijayakar, "Combined surface integral and finite element solution for a three-dimensional contact problem," International Journal for Numerical Methods in Engineering, vol. 31, no. 3, pp. 525-545, 1991.

[42] S. Y. T. Lang, "Graph-theoretic modelling of epicycle gear systems," Mechanism and Machine Theory, vol. 40, no. 5, pp. 511529, 2005. 


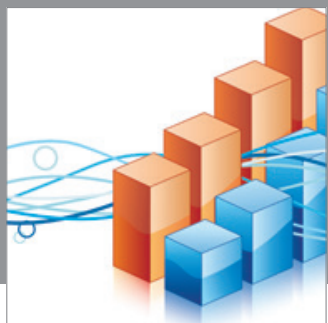

Advances in

Operations Research

mansans

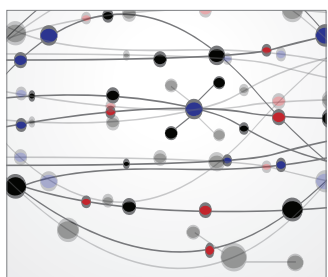

The Scientific World Journal
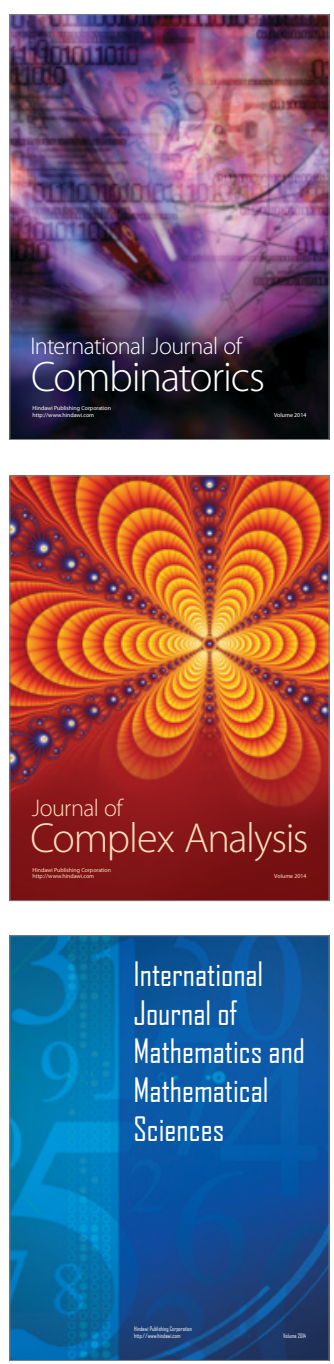
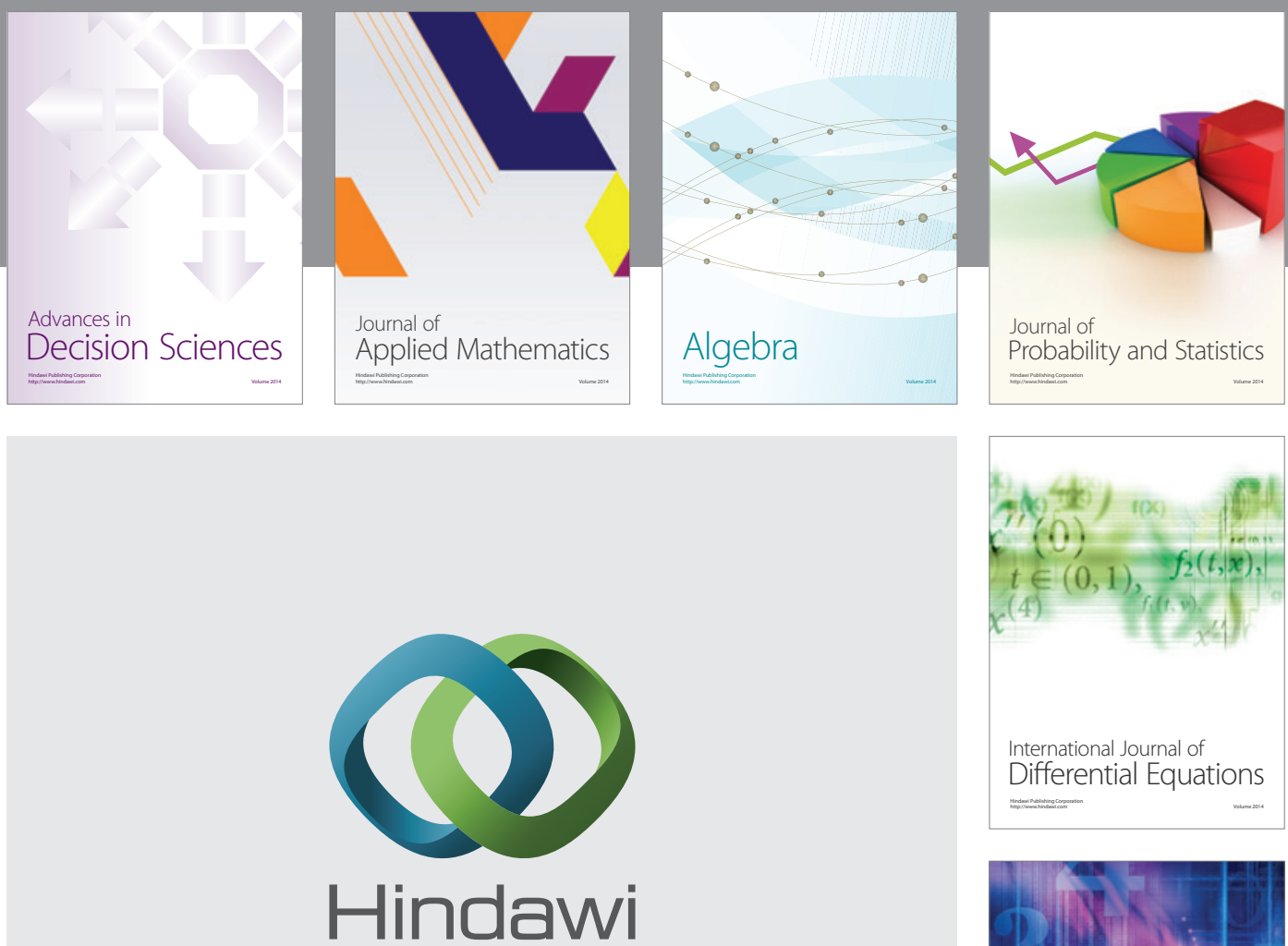

Submit your manuscripts at http://www.hindawi.com
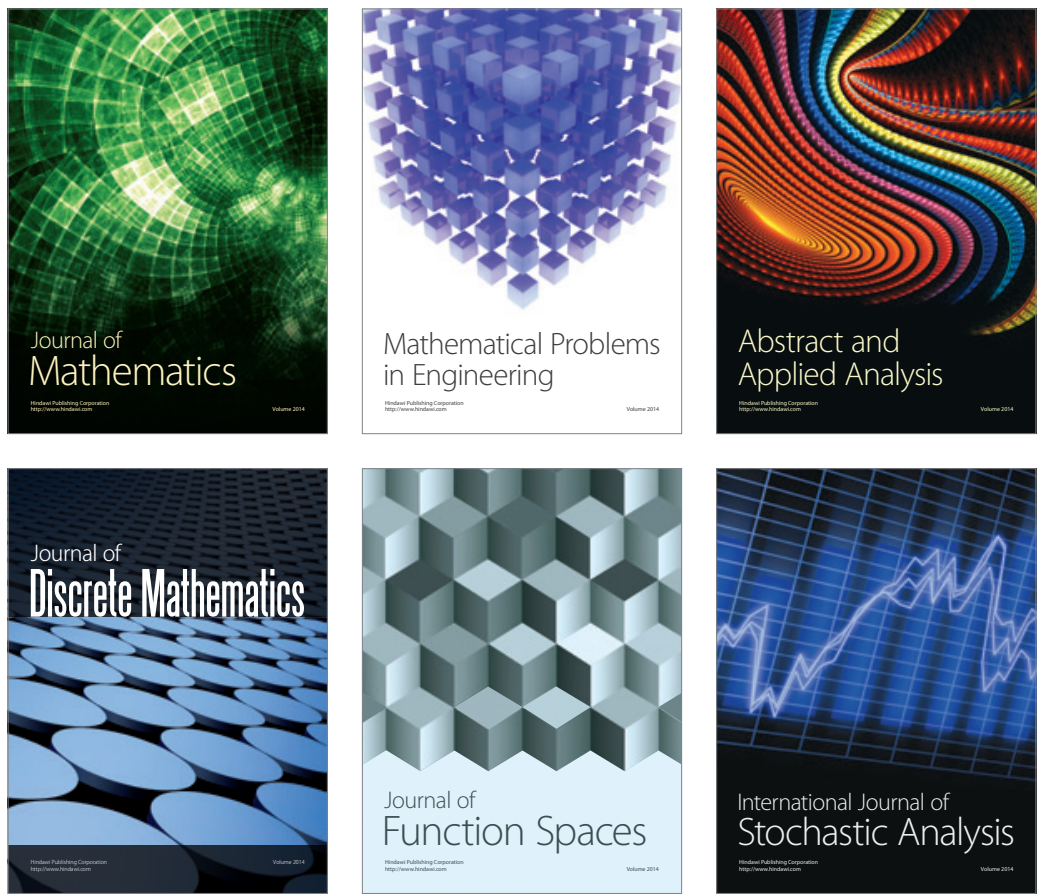

Journal of

Function Spaces

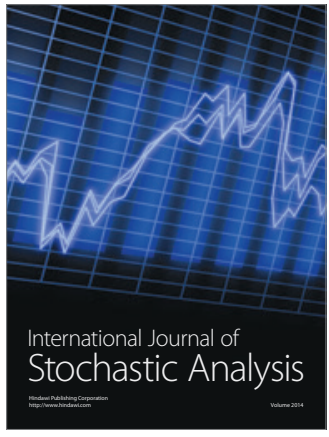

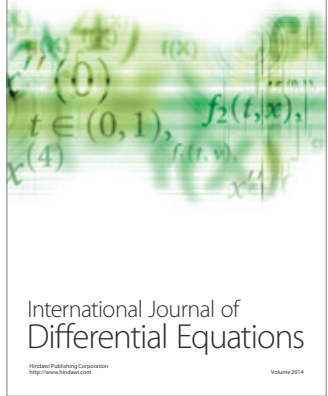
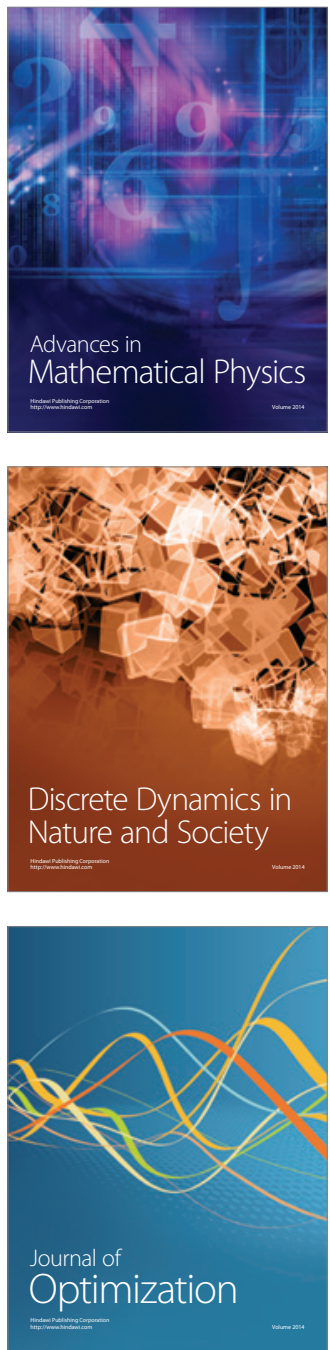